\title{
Correction to: Novel capacitance evaluation model for microelectromechanical switch considering fringe and effect of holes in pull-up and pull-down conditions
}

\section{Kurmendra $^{1}$ (D) Rajesh Kumar ${ }^{2}$}

Published online: 7 January 2020

(C) Springer-Verlag GmbH Germany, part of Springer Nature 2020

\section{Correction to: Microsystem Technologies}

\section{https://doi.org/10.1007/s00542-019-04611-z}

The original version of this article unfortunately contains a typing error. Last term of Eq. (5) and brackets were incorrectly placed while article preparation and the correct version of that equation should be

$C_{1, u}=\frac{\epsilon_{0} A}{g_{0}+\frac{t_{d}}{\epsilon_{r}}}+\frac{2 \in . W}{\pi}\left[\ln \left(\frac{\pi \cdot w}{g_{0}+\frac{t_{d}}{\epsilon_{r}}}\right)+\ln \left(\left(1+\frac{2 t_{b}}{g_{0}+\frac{t_{d}}{\epsilon_{r}}}\right)+2 \sqrt{\left.\left(\frac{t_{b}}{\left.g_{0}+\frac{t_{d}}{\epsilon_{r}}+\frac{t_{b}^{2}}{\left(g_{0}+\frac{t_{d}}{\epsilon_{r}}\right)^{2}}\right)}\right)\right]}\right.\right.$

The changes will be applied subsequently in the Eqs. (6), (7), (8), (9), (10), (12) and (13).
Publisher's Note Springer Nature remains neutral with regard to jurisdictional claims in published maps and institutional affiliations.

The original article can be found online at https:// doi.org/10.1007/s00542-019-04611-z.

\section{Kurmendra}

kurmendra.nits@gmail.com

1 Department of Electronics and Communication Engineering, Rajiv Gandhi University (A Central University), Itanagar 791112, India

2 Department of Electronics and Communication Engineering, NERIST, Nirjuli, Itanagar, India 